\title{
Professional Teaching Analysis and Reform Direction of Industrial Design Major of Engineering in Higher Vocational Colleges
}

\author{
Ying Jiang \\ Jiangxi Environmental Engineering Vocational College, Ganzhou, 341002
}

Keywords: higher vocational education; Industrial Design; teaching analysis; teaching reform

\begin{abstract}
In view of the teaching of Industrial Design major of Engineering, this paper analyzes the teaching object, teaching contents, teaching staff and teaching mode, and probes into the reform direction of Industrial Design major of Engineering in higher vocational colleges.

With the emergence and development of industry, subjects of industrial product design also rise, which is the unity of technology and art, science and aesthetics, application and aesthetics. However, the introduction of "modernism" abroad leads to the unsoundness and hysteresis of the system. Nowadays, Industrial Design cannot meet the needs of the society and the main reason lies in the difference between enterprises and talented people, which is embodied in the characteristics of the subject and teaching.

With the continuous efforts of our country in recent years, the market in the Pearl River Delta and the Yangtze River Delta has gradually matured, realizing a preliminary prosperity of Industrial Design. At present, Industrial Design major based on Engineering has been set up in some comprehensive colleges and universities as well as art colleges. The former is mainly set in the Department of Mechanical Engineering, and the latter is mainly set in the Design Department. In recent years, with the development of higher vocational education, the major of Industrial Design has also been set up in higher vocational colleges, which is also in the Departments of Machinery and Art. Because of their different emphasis on the teaching of specialized courses, there are differences in the implementation.

With the continuous improvement of this major, great changes have taken place in the teaching mode, course design, teaching method, teaching means, teaching staff and so on, especially in the cultivation of innovative ideas.
\end{abstract}

\section{Professional Teaching Analysis of Industrial Design of Engineering}

What Industrial Design needs most is creativity. Without creativity, there is no soul. This requires the design of education system itself has a certain degree of creativity. Secondly, this subject has a strong practicality, which should cultivate students' ability of discovery, practice, analysis and synthesis, oral and written expression, and team cooperation through practical activities.

\subsection{Teaching Object}

Industrial Design belongs to cross and comprehensive subject. Industrial Design major can either recruit students from science or from arts. This will lead to a fuzziness of professional orientation and teaching, which is rare in Engineering majors.

Engineering students pays attention to logic and rationality, but lacks creativity. In the process of study, they despise the training of art courses because they lack the basic knowledge of fine arts and have wrong understandings as well as a blind worship for computer design. This requires professional teachers to do a good job, letting students realize the importance of practice.

For higher vocational students, design major has some difficulties compared with other majors. It not only requires students to have a good comprehensive quality, insight into the market changes, but also requires them to have a certain design ability and skills level. 


\subsection{Teaching Staff Status}

At present, teachers majoring in Industrial Design mainly come from three aspects. First, teachers who are directly engaged in education profession after graduation from colleges and universities. They have a systematic theoretical knowledge, but lack practical experience and professional skills. Second, specialized technical personnel from front-line jobs in enterprises and institutions, who have skills to match their jobs, lack s systematic teaching experience. Third, experts with a certain reputation in the field of Industrial Design who have high professional standards and artistic attainments, but their teaching time is limited. It is difficult to complete a course of teaching.

At present, there is still a certain gap between the present situation of teaching staff and the development demand of Industrial Design major, which can not meet the diversified demands of cultivating talents.

\subsection{Teaching Contents}

Teaching contents of Industrial Design major is a kind of multi-disciplinary cultural integration and structure combination, which involves many aspects of professional knowledge and is a process of long-term accumulation, study and practice. An important task in professional education is to make students make an effective use of their time in colleges to set up an appropriate knowledge structure. Graduates of Industrial Design should have a comprehensive understanding of the design and manufacturing process of market products until they reach the market. They must also have some skills, including creative problem-solving skills, sketching and freehand painting skills, model-making ability, interactive ability, appreciative and expressive ability. In addition, they must master the use of various drawing software.

The teaching contents are mainly arranged for three years, of which two and a half years are required to complete the study and training of specialized courses, and the last half year is for internship training. However, many Industrial Design major offers many courses. Miscellaneous courses occupy most of students' time and the knowledge of the main courses is diluted. The main problem lies in the limitation of mechanical subject. Teachers only pay attention to the cultivation of students’ professional skills, but do not fundamentally improve their abilities.

\subsection{Teaching Mode}

Professional teaching related to Engineering pays attention to logic and reasoning, emphasizing concrete teaching thoughts. Its advantage lies in the rigorous and orderly way of teaching. The teaching mode of majors related to arts attaches attention to divergent thinking, guides students to think about problems and advocates their initiative by visual images. Its advantage is that it can give students free space, and is capable of developing their practical and expressive ability.

All of the above teaching modes have their merits. Teachers can implement different means and methods according to students' specific conditions, or combine these two kinds of teaching to form a new teaching mode. This process requires teachers to be able to control the progress of the project, and is beneficial to arouse students' enthusiasm and study interest.

\section{Reform Direction of Industrial Design Major of Engineering in Higher Vocational Colleges}

With the continuous development of society, product design also needs constant innovation. Enterprise products also should be creative, so as to improve its core competitiveness. Thus, we can see that design innovation is particularly important. In order to respond to the call of the society and meet the needs of the development of enterprises, higher vocational colleges should cultivate innovative talents who can connect with enterprises.

\subsection{Improve Students’ Analytical Ability}

Industrial Design is a major with a strong spatial feature. Teachers should continue to study, explore and reform teaching concepts and mode without sticking to rules. They should use new teaching methods and modes to stimulate students' creativity, guide students to think, and give full 
play to their strengths, try to use a variety of tools to stimulate their thinking. Because this major requires more space, students should have a better understanding of various forms, changes and composition in space. Teachers take a systematic training and more acceptable ways to stimulate students' interests. Thus, it is conducive to achieve the purpose of enabling students to think from multiple perspectives. After the end of knowledge teaching, students should be allowed to complete their works by themselves, and to train thinking and expression.

The modeling design of products is very important in enterprises. Only can innovation design make enterprises develop and progress continuously. The creation of innovative design depends on students' analytical ability, so in the process of practice, students should be given a full play to their imagination and improve the ability to integrate.

\subsection{Targeted Curriculum Setup}

In order to meet the demands of the society for talents of Industrial Design, colleges and universities pay attention to the pursuit of an unified standard of artistic ability and technical level. In the course setup, the Design major of Engineering colleges has also set up basic courses of fine arts. However, the teaching time of higher vocational colleges is less and can not be carried out completely according to this teaching method. It is suggested that higher vocational colleges should break the convention, carry out parallel interactive courses and integrate teaching contents, which not only can be used for short teaching hours, but also can improve practicability. The main practices are as follows:

\subsubsection{Basic courses adopt “Cluster Curriculum Mode”}

Some basic courses are arranged in the beginning of study, and professional courses are intersected according to the modes.

\subsubsection{Professional courses should as much as possible be "in common, targeted and new"}

"In common" means that basic courses should be used generally. "Targeted" refers to that professional courses should be aimed at students' professional skills cultivation. "New" means that the professional courses should match the needs of enterprises in the corresponding time.

\subsubsection{Open and flexible elective system}

Elective courses may not be subject to professional or curriculum restrictions. Elective credits can be obtained through social practice, extracurricular interest groups, participation in tutorial projects or student competitions.

\subsubsection{Apply computer digital technology}

Taking into account the actual level of arts of Engineering students in higher vocational education, on the one hand, we need to strengthen the training of hand-drawing, sketch and design skills. On the other hand, we should use computer digital technology as far as possible to make up for the deficiency of hand-drawing ability and to improve the performance of design, which can bring students' enthusiasm into full play.

\subsection{Flexible and Diverse Teaching Methods}

A single teaching means can not adapt to the current teaching, the teaching of Industrial Design should be integrated with each other and its advantages and disadvantages complement each other, so as to reflect their professional characteristics and form a new teaching method.

\subsubsection{Open arts teaching idea}

The traditional teaching method is a process in which teacher teaches and students imitate, accept, and learn. In Industrial Design major, teachers are the guides, organizers, motivators and explorers in teaching courses. They can tap students' potential and improve their creativity. Therefore, teachers must be students-oriented and arouse their enthusiasm. 


\subsubsection{Teaching method of higher vocational education based on practice}

Practice is the only criterion for testing truth. If there is only skills and no creativity, it will be doomed to follow the path of others forever, lacking initiative and creativity. A qualified Industrial Designer should have a certain level of skills and the most innovative experience. Therefore, the teaching method based on practice is the teaching idea of higher vocational education.

\subsubsection{Cultivation of design practice ability}

Students participate in the practice of higher vocational college mainly through two ways. Firstly, practice opportunity is obtained through the connection between teachers and enterprises. Secondly, students can participate in all kinds of competition activities in the society. The first way is limited in number, through which, students' enthusiasm for learning and work can be stimulated. The second way has a large coverage, which can lead design activities to be norm and act as the main means for students to participate in the practice. However, the competitors are relatively more and the low award rate will strike students' enthusiasm. At this time, teachers should offer guidance correctly, correct students' thoughts, help them find the gap and improve their level.

\subsection{Cultivate a Team of Excellent Teachers}

Design needs both sensibility and rationality, but the perceptual thinking of Engineering students is not active enough. In teaching, we should strengthen the training of perceptual thinking. For example, we can improve the ability of perceptual thinking from special training of visual perception. In the construction of teachers, we should pay attention to the cultivation of high-level teachers. From this point of view, we can draw lessons from Bauhaus's approach that is to combine artists and designers, combine masters with craftsmen, and let arts teachers and Engineering teachers cross-teach and discuss.

Teachers should avoid too much subjective judgment. In fact, some Engineering students have poor painting foundation and more rational thoughts than perceptual thoughts, but this can not let us deny their potential. The key is to see what kind of teaching methods and modes can guide students' thinking. The potential of students is excavated by teachers. Therefore, teachers should use their own knowledge and corresponding judgments to guide students. Through efforts, students will dare to communicate, constantly exert their potential, and carry on the study instruction in the collision of knowledge. This helps students to expand the depth and breadth of study.

\section{Conclusion}

The development of Industrial Design is also uneven because of different economic conditions in different regions of China. Conditions of running schools in different regions differ and demands of different markets are also different, which lead to the trend that Industrial Design cannot be unified, and it is difficult to fix an unified standard mode. Therefore, the development of Industrial Design must be diversified, constantly changing with the demands of market. From this point of view, the teaching of Industrial Design major in our country must be hierarchical and targeted, and higher vocational education is an indispensable part.

\section{References}

[1] Subcommittee on Teaching Instruction of Industrial Design. Research on the Development Strategy of Industrial Design Major [R]. Communication of the Teaching and Guiding Committee of Science and Engineering in Colleges and Universities, 2005.

[2] Lv Xinxin. Discussion on Art Cutting in the Professional Teaching of Industrial Design of Engineering [J]. Journal of Guangdong Polytechnic Normal University, 2009(6):71-73.

[3] Ye Dan, Dong Jiejing, Jiang Ju, etal. Present situation, problems and Countermeasures of Industrial Design Major [R]. Hangzhou: Department of Industrial Design of Hangzhou Dianzi University, 2010. 
[4] Zeng Xuejun, Zheng Lingyan. Discussion on Computer Network Practice Teaching in Higher Vocational Colleges [J]. China Science and Technology Expo, 2009 (7): 226-227.

[5] Ding Songjian. “Technical Humanity” and "Reasonable Humanity": On Contemporary Art Education and Its Social status [J]. Journal of Fine Arts: 2001, 28 (1): 52-54.

[6] Song Mingming. Concept and Practice of Modern Design Education in Germany [J]. Liaoning Fine Arts Publishing House, 2000.

[7] Gu Yiming, Cao Yuhua, Wang Shi, Xu Ning. Exploration of Industrial Design Teaching Mode Reform in Engineering Colleges [J]. Educational Theory and Practice, 2009(15).

[8] Du Lian. Teaching Research and Exploration of the Course of Industrial Design History [J]. Journal of Yangtze University (Social Science Edition), 2009 (2). 